\title{
THE GENETIC BACKGROUND OF SOUTHERN IRANIAN COUPLES BEFORE MARRIAGE
}

\author{
Nariman $\mathrm{A}^{1}$, Sobhan $\mathrm{MR}^{2}$, Savaei $\mathrm{M}^{3}$, Aref-Eshghi E ${ }^{4}$, Nourinejad R', \\ Manoochehri $\mathrm{M}^{5}$, Ghahremani $\mathrm{S}^{6}$, Daliri $\mathrm{F}^{7}$, Daliri $\mathrm{K}^{1, *}$
}

*Corresponding Author: Dr. Karim Daliri, Department of Human Genetics, Behbahan Faculty of Medical Sciences, Bashir Boulevard, Behbahan, Iran. Tel: +98-9374140937. Fax:+98-9374140937. E-mail: karimdaliri@ gmail.com

\begin{abstract}
Genetic service for couples plays an increasingly important role in diagnosis and risk management. This study investigated the status of consanguinity and the medical genetic history (effectiveness and coverage of medical genetic services) in couples residing in a city in southern Iran. We questioned couples who were referred to Behbahan Marital Counseling Center, Behbahan, Iran, during the period from January to November 2014, to obtain information on consanguinity, disease history, and previous referral to a medical genetics center. For the collected data was obtained descriptive statistics with STATA 11.0 software. A total of 500 couples were questioned. Mean age was $24.8 \pm 5.2$ years. Almost one quarter (23.4\%) of the couples were consanguineous. Consanguinity was almost twice as common in rural areas as in urban areas (33.9 vs. $19.2 \%, p=0.001)$. Only a few couples $(\sim 3.0 \%)$ had ever been referred for genetic counseling. The main reason for

\footnotetext{
${ }^{1}$ Department of Human Genetics, Behbahan Faculty of Medica Sciences, Behbahan, Iran

${ }^{2}$ Department of Orthopedics, Shahid Sadoughi University of Medical Sciences, Yazd, Iran Sciences, Behbahan, Iran

${ }^{4}$ Faculty of Medicine, Memorial University of Newfoundland, St. John's, NL, Canada

${ }^{5}$ School of Medicine, Shahroud University of Medical Sciences, Shahroud, Iran Sciences, Tehran, Iran

${ }^{7}$ Department of Psychology, Islamic Azad University, Marvdasht Branch,Marvdasht, Iran
}

${ }^{3}$ Department of Anesthesiology, Behbahan Faculty of Medical

${ }^{6}$ Department of Clinical Psychology, Iran University of Medical
\end{abstract}

previous genetic counseling was consanguinity $(85.7 \%)$. The majority of the participants $(96.3 \%)$ had never been tested for any genetic conditions. Our findings suggest that only a small proportion of couples in Khuzestan Province, Iran (Behbahan City) were receiving adequate genetics care. This may reflect the limited accessibility of such services, and inadequate awareness and education among the care providers.

Keywords: Genetic counseling; Genetic testing; Iran

\section{INTRODUCTION}

The National Society of Genetic Counselors (NSGC) has introduced and approved the following definition of genetic counseling: "the procedure of helping people to comprehend the medical and familial implications of genetic contributions to the disease." This procedure combines: 1) the interpretation of medical histories to evaluate the chance of the disease occurrence, and 2) counseling to improve choices and adaptation to the current risk [1]. About one billion people in the world live in communities that accept consanguineous marriage [2]. In Middle East and Southern Indian populations, consanguineous marriages are socially respectable and about one-third of all marriages are between first cousins [3]. Moreover, Saadat et al. [4], reported a $38.6 \%$ rate of consanguineous marriages in Iranian couples. The rate is reported to be much higher (up to $73.0 \%$ ) in the parents of individuals with rare genetic disorders [5].

Consanguineous marriage is defined as a relationship between two individuals as second cousins or closer. Parents who are first cousins have an extra risk for having a child with an autosomal recessive disease. Moreover, 
the risk of fetal loss due to lethal autosomal recessive disorders is higher in consanguineous marriages than in the general population [6]. Therefore, reproductive health can be threatened by some lethal autosomal recessive disorders in consanguineous marriages [7].

Over 6000 heritable genetic disorders exist, many of them, such as $\beta$-thalassemia ( $\beta$-thal), are fatal or debilitating. The genetic consultation can include taking a family history, medical examination, and essential medical tests. For couples with a family history of certain genetic disorders, specific genetic tests are recommended. Due to the high frequency of $\beta$-thal in the Iranian population, it is mandatory for all couples who plan to marry to undergo a screening test for detection of $\beta$-thal carrier status. Carriers who are identified by screening are referred for genetic consultation [7].

To provide effective and helpful genetic counseling services, clinical professionals need sufficient knowledge about the profile of the referred individuals [8]. Furthermore, the recent development of highly demanding genetic techniques such as whole genome sequencing (WGS), whole exome sequencing (WES) and comparative genomic array $(\mathrm{aCGH})$, have created new areas of genetic counseling. Therefore, it is important to have clear guidelines for the interpretation of the results of these tests for highly consanguineous communities [9]. The primary purpose of this study was to obtain information on the genetic history and genetic services offered to couples who intend to marry in Behbahan City, Iran.

\section{MATERIALS AND METHODS}

Data Collection. The main proposal was approved by the Research Ethics Committee of Behbahan School of Paramedicine. All participants were assured that they had the right to refuse to sign the consent form. For the pilot study, 500 participants were selected from couples who were referred to the Behbahan Marital Counseling Center, located in Behbahan, a city in southern Iran, during the period from January to November 2014, to obtain information on consanguinity, disease history, and previous referral to a medical genetics center.

The genetic counseling questionnaire included demographic data (age, sex and ethnicity), and information used to record different aspects of their medical history. Regarding genetic counseling services, we asked participants: "Have you ever been referred for genetic counseling before?" For those who answered yes, we asked them to provide the reason(s) for the referral(s) in a free-text item.
We also asked participants: "Have you ever been referred for genetic testing, and if so, what were the results of the tests?"

Other items evaluated their genetic background. One item asked respondents to specify whether their marriage was consanguineous (inbred) or non-consanguineous (outbred). Couples who were consanguineous were asked to indicate the degree of consanguinity. In a second item, the participants were asked to report any genetic diseases in their siblings or any experiences with infertility.

Data Analysis. Descriptive statistics and classical tests of hypotheses were conducted using STATA 11.0 software (http://en.softonic.com/s/ spss-11.0-free-full-version?ex-TOP-207.3).

\section{RESULTS}

Our study included a total of 500 couples. The participants ranged in age from 14 to 49 years old (mean age 24.8 \pm 5.2 years) and they all were of Southern Iranian origin. More than $70.0 \%$ had at least a high school diploma or an academic degree, and about $50.0 \%$ were employed. The area of residence was rural for $28.0 \%$ of the participants and metropolitan for $72.0 \%$.

Almost one quarter (23.4\%) of the couples were consanguineous. Consanguinity was more common in rural areas (33.9 vs. $19.2 \%, p=0.001)$ as compared to urban regions. Of the couples who were related, $65.0 \%$ were first degree relatives and $35.0 \%$ were second degree or more distant relatives.

As shown in Table 1, 97.0\% of participants had never been referred for genetic counseling, whereas $8.2 \%$ of them reported having attended at least one genetic counseling appointment before the time of the study. The most frequent reason for previous genetic counseling was consanguineous marriage (Table 1).

The results of medical history and earlier genetic tests of couples reported by respondents are summarized

Table 1. Genetic counseling appointments $(n)$.

\begin{tabular}{|l|c|}
\hline Ever met a genetic counselor? & $\boldsymbol{n}$ \\
\hline No response & 459 \\
\hline Yes response & 41 \\
\hline Reasons for genetic counseling referral & \\
\hline Consanguineous marriage & 12 \\
\hline Anemia & 2 \\
\hline No useful data & 27 \\
\hline Total & 41 \\
\hline
\end{tabular}

Genetic counseling referrals $(n=500)$. 
Table 2. Genetic history of the couples.

\begin{tabular}{|l|c|}
\hline Medical Complications & $\boldsymbol{n ( \% )}$ \\
\hline Abortion & $42(8.3)$ \\
\hline Mental retardation & $11(2.1)$ \\
\hline Still birth & $5(1.2)$ \\
\hline No genetic complications & $442(88.4)$ \\
\hline Total & $500(100.0)$ \\
\hline
\end{tabular}

Table 3. Results of genetic tests (self-reported).

\begin{tabular}{|l|c|}
\hline Tests & $\boldsymbol{n ( \% )}$ \\
\hline No test & $493(98.6)$ \\
\hline Normal & $5(1.0)$ \\
\hline Abnormal & $2(0.4)$ \\
\hline
\end{tabular}

in Tables 2 and 3, respectively. Most participants (98.6\%) had never undergone any genetic tests, and of those who had been tested, abnormal results were reported by a small proportion of the total population $(0.4 \%)$.

\section{DISCUSSION}

To the best of our knowledge, this is the first study in Khuzestan Province, Iran (Behbahan City) to investigate the genetic background of couples before marriage. We found that most respondents $(97.0 \%)$ had never been referred for genetic counseling, and their health care providers had only referred a few of them for genetic testing $(98.6 \%)$ despite the high rate of consanguinity. These findings suggest that most health service providers in our setting were not aware of or underestimated the importance of genetic services. Our respondents were also mostly unaware of the type of tests they had undergone. These suggest that both health care providers and the public would benefit from training in the general concepts of genetics and their importance before marriage. This cannot be achieved without increasing the collaboration between genetic counseling centers, genetic testing laboratories and health service providers.

DNA copy number variants (microdeletions and duplications), single gene and complex disorders, chromosomal aberrations and epigenetic disorders are the main categories of potential causes of genetic problems. With the progress in molecular genetics of diseases, each year about 10 to 15 new tests become available for clinical genetic testing [10]. As more genes are discovered and the etiology of more genetic disorders is understood, the role of genetic counseling in health care systems is expected to increase. Genetic counseling is the process of helping people to understand the medical, psychological and familial implications of genetic contributions to disease. Counseling should include assessing the chances of occurrence or recurrence of a disease, management and prevention. In our study, the main reason for genetic counseling was consanguinity, whereas other forms of assessments were mainly ignored. These results are comparable to those by Fathzadeh et al. [11] who reported consanguinity as the primary reason for referrals for genetic counseling. In populations with high rates of consanguineous marriages, an improvement in the public health genetic service as well as the education of the public about the risks of consanguineous marriages is strongly suggested to reduce the risks. Apart from this, the integration of the genetics service to the local Primary Health Care facility that is currently performed at the rural and metropolitan levels in the province, would be the first step to improve clinical genetic services in this region. In addition, a number of reports have noted that health care providers may be inconsistent in the counseling they provide for consanguinity, so in this area, they need to increase their awareness of genetic issues, possibly through self-learning and official education, in order to make appropriate referrals [12].

Conclusions. The implications of our findings are useful from both theoretical and practical standpoints. Despite the key role of genes in the etiology of different human diseases, some medical professionals may underestimate their actual value in the process of prevention, diagnosis and treatment. All couples who plan to marry, especially those who are related by consanguinity, should be informed of the risks, benefits, and possible outcomes of pregnancy and parenthood through genetic counseling and public education via the media. Furthermore, we strongly recommend closer collaboration between clinical genetic counseling centers, genetic testing laboratories and health service providers at marital counseling centers, as well as regular training for health service providers such as physicians and nurses in basic and applied concepts in human and medical genetics.

Declaration of Interest. The authors report no conflicts of interest. The authors alone are responsible for the content and writing of this article.

\section{REFERENCES}

1. Zorrilla M, Yatsenko AN. The genetics of infertility: Current status of the field. Curr Genet Med Rep. 2013; 1(4): 247-260. 
2. Bittles AH, Black ML. Evolution in health and medicine Sackler colloquium: Consanguinity, human evolution, and complex diseases. Proc Natl Acad Sci USA. 2010; 107(Suppl 1): 1779-1786.

3. Tadmouri GO, Nair P, Obeid T, Al Ali MT, Al Khaja N, Hamamy HA. Consanguinity and reproductive health among Arabs. Reprod Health. 2009; 6:17. doi: 10.1186/1742- 4755-6-17.

4. Saadat M, Ansari-Lari M, Farhud DD. Consanguineous marriage in Iran. Ann Hum Biol. 2004; 31(2): 263-269.

5. Aref Eshghi E, Masoumi P. Genetic and demographic analysis of retinitis pigmentosa in Iran during 2007-2008. Med Sci J Islamic Azad Univ Tehran Med Branch. 2012; 22(1): 78-84. (www.iau-tmuj.ir/ browse. php?a_id=545\&sid=1\&slc.lang-en)

6. Rull K, Nagirnaja L, Laan M. Genetics of recurrent miscarriage: Challenges, current knowledge, future directions. Front Genet. 2012; 3: 34. doi: 10.3389/ fgene.2012. 00034.

7. Helm BM. Exploring the genetic counselor's role in facilitating meaning-making: Rare disease diagnoses. J Genet Couns. 2015; 24(2): 205-212.
8. Lee H, Deignan JL, Dorrani N, Strom SP, Kantarci S, Quintero-Rivera F, et al. Clinical exome sequencing for genetic identification of rare Mendelian disorders. JAMA 2014; 312(18): 1880-1887.

9. Zlotogora J. Population programs for the detection of couples at risk for severe monogenic genetic diseases. Hum Genet. 2009; 126(2): 247-253.

10. Boland PM, Ruth K, Matro JM, Rainey KL, Fang CY, Wong YN, et al. Genetic counselors' (GC) knowledge, awareness, understanding of clinical nextgeneration sequencing (NGS) genomic testing. Clin Genet. 2014; 88(6): 565-572.

11. Fathzadeh M, Bigi MA, Bazrgar M, Yavarian M, Tabatabaee HR, Akrami SM. Genetic counseling in southern Iran: Consanguinity and reason for referral. J Genet Couns. 2008; 17(5): 472-479.

12. Ormond KE. From genetic counseling to "genomic counseling." Mol Genet Genomic Med. 2013; 1(4): 189-193. 